\title{
A revista Saúde em Debate como fonte e objeto de estudo
}

\author{
The magazine Saúde em Debate \\ as a source and object of study
}

\author{
Daniela Carvalho \\ Sophia \\ Pesquisadora do Museu de \\ Astronomia e Ciências Afins. \\ Rua General Bruce, 586 \\ 20921-030 - Rio de Janeiro - RJ \\ - Brasil \\ danielasophia@mast.br
}

SOPHIA, Daniela Carvalho. A revista Saúde em Debate como fonte e objeto de estudo. História, Ciências, Saúde - Manguinhos, Rio de Janeiro, v.20, supl., nov. 2013, p.1403-1412.

\section{Resumo}

A presente nota de pesquisa busca divulgar estudo sobre o Centro Brasileiro de Estudos da Saúde e o movimento de reforma sanitária desenvolvido no âmbito do Programa de História das Ciências e da Saúde Pública da Casa de Oswaldo Cruz. Atém-se à revista Saúde em Debate, periódico do Centro, devido à relevância que teve na área ao longo dos dez anos de publicação. A utilização da revista na pesquisa deu visibilidade a questões pertinentes à participação de seus membros na reforma sanitária. Enfatiza-se o fato de que a utilização do periódico como fonte e objeto de estudo para fomentar a produção de pesquisa na área da saúde merece investigação mais ampla.

Palavras-chave: história; história da saúde pública; Centro Brasileiro de Estudos da Saúde (Cebes).

\section{Abstract}

This research note is about a study of Centro Brasileiro de Estudos da Saúde (Brazilian Center for Health Studies, Cebes) and the sanitation reform movement conducted within the ambit of the History of Science and Public Health program at Casa de Oswaldo Cruz. The study focuses on Saúde em Debate, the periodical published by Cebes, because of the importance it had during its ten-year existence. The use of the periodical in the research brought to light some issues concerning the participation of its members in the sanitation reform. It is shown how the use of the publication as a source and object of study in research in the area of health deserves broader investigation.

Keywords: history; history of public health; Centro Brasileiro de Estudos da Saúde (Cebes). 
Es ssa pesquisa aborda a história do Centro Brasileiro de Estudos da Saúde (Cebes) e de sua atuação no Brasil entre 1976 e 1986, quando a instituição se tornou o ponto de encontro de médicos e sanitaristas.

O Centro foi lançado durante a 28a Reunião da Sociedade Brasileira para o Progresso da Ciência (SBPC), em julho de 1976, em Brasília. Na Assembleia Geral da SBPC, quando cerca de cinco mil pessoas lotavam o auditório do evento, após cinco horas de calorosas discussões, foram aprovadas moções de crítica ao governo do general Ernesto Geisel e em favor da liberdade de expressão para o livre exercício da prática científica. Nesse clima, foi anunciada a fundação de um centro de estudos voltado para os problemas de saúde. A instituição, recém-criada, foi registrada em 8 de setembro de 1976 pelo médico José Ruben de Alcântara Bonfim no Terceiro Cartório de Registro Civil das Pessoas Jurídicas, como Centro Brasileiro de Estudos da Saúde, abreviadamente Cebes. "Era uma entidade civil, sem fins lucrativos, de duração determinada, com sede e foro na cidade de São Paulo" (Cebes, 1976, p.1).

Espaço de discussão de novas formas de atuação dos médicos frente à realidade dos serviços de saúde pública, financiado com recursos próprios, o Cebes surgiu com dupla função: a primeira, de natureza político-ideológica, era concorrer para o aprimoramento das instituições democráticas que pugnassem por medidas que promovessem o bem-estar físico e mental. A segunda função, de natureza técnico-científica, consistia na promoção de pesquisas sobre os fatores determinantes da saúde do homem.

Tais objetivos foram reiteradamente apresentados em Saúde em Debate, revista de divulgação da entidade. Sua característica foi aliar conhecimento científico e político aplicado à gestão das políticas de saúde por meio de uma visão crítica e alternativa ao sistema de saúde vigente. De fato, entre 1976 e 1986 observamos que Saúde em Debate envidara esforços para divulgar em maior ou menor grau - a mensagem de que as políticas de saúde estariam sendo geridas de forma ineficiente e de que os serviços de saúde, se bem geridos, poderiam gerar melhoria das condições de saúde da população. Essa mensagem seria ressaltada por meio da divulgação de artigos, fotografias, tirinhas, caricaturas e mesmo em seus editoriais. Todas essas aparições pareciam privilegiar imagens negativas da política, do sistema de ensino médico e do sistema de saúde.

A revista tinha apresentação gráfica simples, acompanhada por ilustrações que expressavam o caráter político da entidade. O número de páginas variava de 60 a 80, sendo perceptível a variação em tempos de dificuldade financeira, prenúncio de uma crise que modificaria o fluxo das atividades do Centro. O Cebes não dispunha de gráfica própria. A produção dos exemplares entre 1976 e 1980 era feita na Cerifa Gráfica, localizada nos Jardins Paulistas, e impressão na Rumo Gráfica Editora, localizada na rua Aracy, no município de São Paulo. A partir de outubro de 1977, a composição passa a ser feita na Literal Serviços, e a impressão e o acabamento, na Imprensa Metodista.

A capa continha o nome da revista centralizado na parte superior e, imediatamente abaixo, o subtítulo Revista do Centro Brasileiro de Estudos da Saúde, imprimindo o registro institucional, marca que acompanharia a instituição e o periódico por todo o período estudado. Além disso, continha o ano, o número e os meses de cobertura. É significativo o fato de que discussões de ordem político-partidária estivessem ausentes da publicação no período inicial de suas atividades como condição para sua circulação, em virtude da conjuntura de repressão 
e censura aos meios de comunicação da época. No primeiro número, aliás, seus editores registraram a publicação na Divisão de Censura de Diversões Públicas do Departamento de Polícia Federal sob o número 1710-P209/73. A mesma marca foi registrada no Instituto Nacional de Propriedade Intelectual (Inpi) sob o número 003038 no dia 4 de fevereiro de 1977.

Seguindo os passos de Dutra (2005, p.40), tomamos a revista como produção social e cultural, transformando-a em objeto da história e, dessa forma, em unidade de compreensão. Isso significa situá-la em função da comunidade a que pertence e reconhecer seu ambiente de utilização, assim como os nexos com as discussões intelectuais e políticas da época. Consideramos o periódico não somente como fonte, mas também como objeto privilegiado de análise, posto ter sido um importante instrumento de consolidação, nos meios acadêmicos e políticos, da proposta da reforma sanitária. Sua produção não significou apenas o registro de opiniões médicas, mas a memória escrita de um grupo de intelectuais, ou seja, a sistematização das experiências da época em que foram montadas, organizadas e registradas.

Tendo feito parte, a seu modo, da rede intelectual organizada em torno do Cebes, e contribuindo cada vez mais para seu fortalecimento, o periódico representou um veículo de discussões e influências que merecem ser analisadas. Canal de divulgação de insatisfações e anseios do grupo, cuja proximidade com instituições acadêmicas significou o fortalecimento de laços e o desenvolvimento de novas redes - primordialmente o exercício político da atividade intelectual, atividade relevante para o movimento da reforma sanitária -, o estudo de Saúde em Debate nos parece de fundamental importância para que possamos compreender melhor o próprio papel social que o movimento sanitário, por meio das atividades do Centro, construiu durante o período.

Assim, refletir sobre o papel da revista no contexto de atuação do Cebes significa pensar algumas questões: qual era a linha editorial da publicação? quem eram os responsáveis e os colaboradores mais assíduos? em quais instituições se formaram? como era composto o círculo intelectual a seu redor? qual a natureza dos conteúdos veiculados pela revista? como era estruturada internamente? qual era seu público-alvo? como a publicação se relacionava com a formulação de políticas públicas de saúde no Brasil e na própria construção do campo da saúde coletiva? qual era o olhar do grupo sobre a reforma sanitária? quais os principais temas, presentes em cada conjuntura, que alimentavam a saúde coletiva? quais eram os conhecimentos produzidos? a que tradições intelectuais era vinculada? As respostas a essas questões contribuirão para a compreensão da densidade dos embates do Centro em torno de projetos de saúde pública que, longe de se esgotarem em si, dialogavam intensamente com os dilemas de seu tempo.

Com o intuito de caracterizar a linha editorial da publicação e o grupo intelectual que se reuniu em torno de sua edição, assim como de examinar o posicionamento de seus editores frente à reforma sanitária, analisamos e interpretamos o material publicado no decorrer de seus primeiros 16 números.

Exame mais detalhado da publicação nos sugere muito sobre seu perfil acadêmico. A apresentação dos artigos em formato acadêmico foi gradativamente ganhando espaço sobre os textos de caráter político. Esses artigos eram estruturados com introdução, objetivo, apresentação, metodologia, desenvolvimento e conclusão. Para possibilitar a transição de um perfil quase exclusivamente político para um formato acadêmico, normas para publicação de 


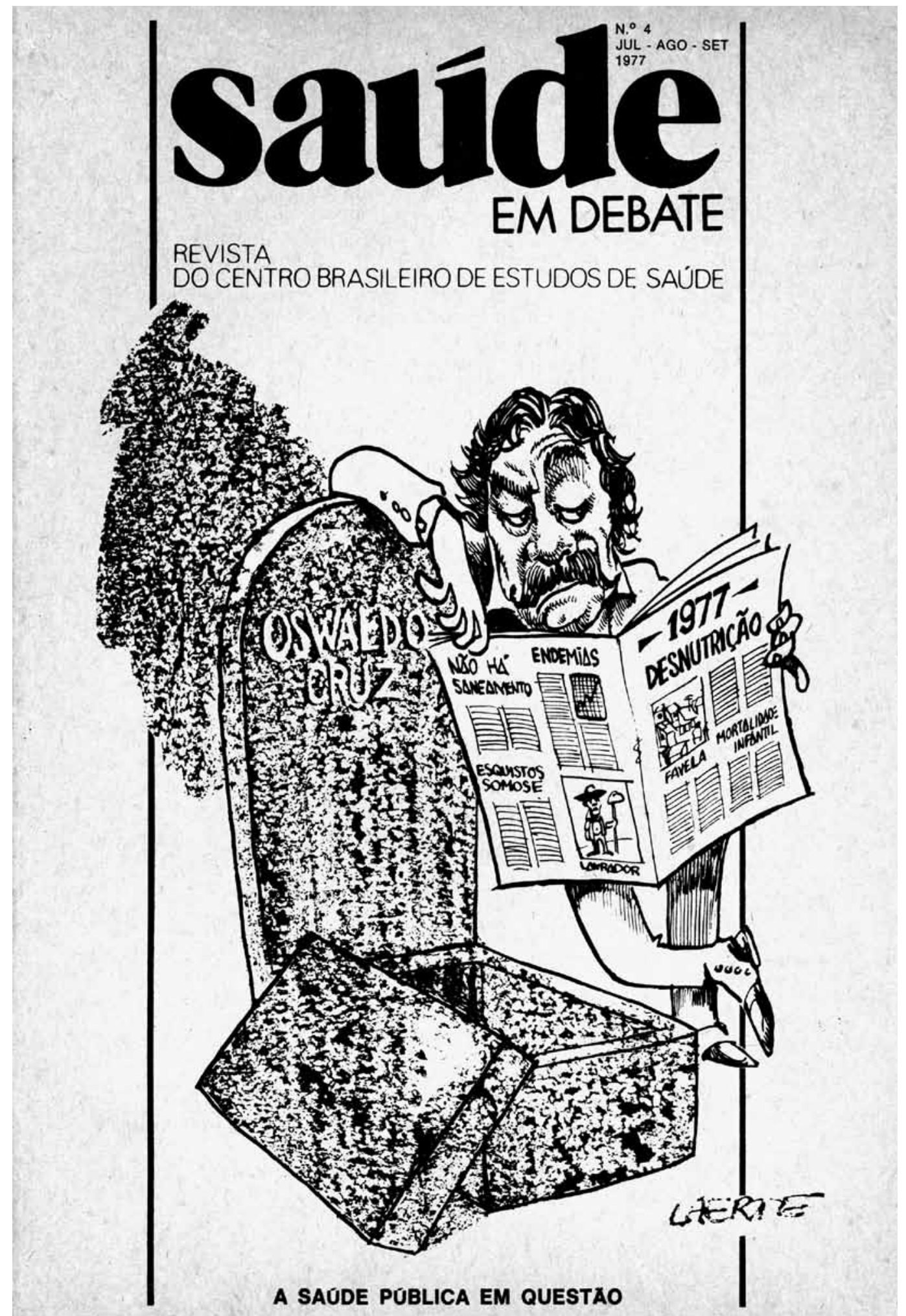

Figura 1: Capa de Saúde em Debate, número 4 (jul.-set. 1977) 
artigos foram criadas e eram apresentadas nas páginas finais da revista, com recomendações expressas dos editores para que os postulantes à publicação as seguissem. O caráter acadêmico da revista caracteriza-se também pela adoção, formal e sistemática, dos procedimentos de avaliação de originais encaminhados para publicação. Durante os dois primeiros anos, no período correspondente a 1976 e 1977, o conselho editorial assumiu a dupla função de condução das atividades editoriais e de gestão do Centro.

Através da composição do conselho editorial podemos perceber a relação que o Centro mantinha com a universidade no período. O conselho editorial de Saúde em Debate era composto por médicos egressos do primeiro curso de especialização em saúde pública para médicos em nível local, promovido pela Faculdade de Saúde Pública da Universidade de São Paulo, realizado no primeiro semestre de 1976. A experiência e o convívio de mestres, professores, alunos e gestores proporcionou a agregação do grupo e a formação de uma linha de pensamento que iria acompanhar toda a trajetória editorial do periódico, anunciando o tom dos debates.

De fato, a biografia dos integrantes do grupo diretor do Centro nos mostra a pujante relação que seus membros mantiveram com a academia no período: a trajetória da quase totalidade dos dirigentes do Cebes registra, senão o diploma, pelo menos uma passagem pela escola de medicina. Esses homens, militantes da saúde pública e defensores de valores democráticos, empenhados em examinar a realidade nacional e em encontrar soluções para os problemas sanitários do país, passam a produzir um tipo de conhecimento e de informação que encontra como meio de divulgação não só a revista Saúde e Debate, mas também livros produzidos em parceria com a Editora Hucitec. Além de médicos, eram vinculados aos Departamentos de Medicina Preventiva e Social, fonte rica de referências às páginas de Saúde em Debate. O resultado de levantamento realizado no periódico relativo aos dez primeiros anos de atividade do Centro mostrou que 52\% dos membros pertencentes à diretoria nacional do Cebes exerciam atividade docente, distribuídos nas seguintes instituições: Universidade do Estado do Rio de Janeiro (Uerj), 27\%; Universidade de São Paulo (USP), 28\%; Universidade Estadual de Campinas (Unicamp), 18\%; Escola Nacional de Saúde Pública (Ensp), 18\%; e Universidade Estadual de Londrina (UEL), 9\%.

A incursão ao periódico permite ainda abordar os debates relacionados ao surgimento do campo acadêmico da saúde coletiva, mostrando como se deu sua institucionalização no Brasil. Os editorialistas da revista trouxeram à luz, por meio da publicação de artigos e editoriais, ampla discussão que abordava criticamente a teoria preventivista, até então hegemônica na análise dos problemas de saúde. Nessa revisão, promovida pelos debates acadêmicos, o estudo do processo saúde/doença teria como foco não mais o indivíduo ou seu somatório, mas a coletividade e a distribuição demográfica do processo da saúde e da doença (Escorel, Nascimento, Edler, 2005).

As conclusões do doutoramento do médico Antônio Sérgio da Silva Arouca são publicadas na primeira edição de Saúde em Debate (Arouca, 1976). Com o título O dilema preventivista: contribuição para compreensão e crítica da medicina preventiva, para o grupo fundador do Cebes a tese foi considerada um marco divisor de águas que dá início à teoria social da medicina no país (Arouca, 2003). Tendo como alicerce seu trabalho de doutoramento, passa a ser propagada uma teoria médico-social que analisa como os problemas se processam no campo 
da saúde no Brasil. Nessa abordagem, a ciência deixa de ser percebida como neutra, e a teoria passa a ser vista como um instrumento de luta política, com a realidade sanitária como seu objeto de estudo e intervenção política (Escorel, 1998, p.64). É interessante a contribuição que essa revisão demonstra ter na construção de propostas de alteração de políticas públicas. Através de diálogos permanentemente expressos nas páginas de Saúde em Debate sobre ideias, pensamentos, doutrinas e visões de mundo em direção à construção de alternativas para a gestão e o planejamento da saúde, percebemos que um novo desenho de política, enfim, estava sendo esboçado.

Para compreender a relação entre ciência e política no movimento sanitarista do período recente percorremos as diferentes temáticas que permearam o periódico, refletindo sobre os embates aí engendrados, enfatizando as controvérsias que movimentaram o Cebes no período proposto. Envolvidos em tensões decorrentes da apresentação de diferentes propostas de transformações nas políticas de saúde que mobilizavam todo o país, os cebianos buscavam constantemente atualizações em suas carreiras acadêmicas e profissionais, fato que geraria intensas dissidências entre eles. Acreditamos que tais conflitos não representassem apenas discordâncias em torno de diferentes propostas de alteração do quadro da saúde, pensadas como meios de superação de desigualdades e injustiças. Eram, principalmente, posicionamentos construídos por relações constituídas e redefinidas mediante tensões que se manifestavam em conjunturas de maior ou menor abertura política e da maior ou menor visibilidade política do grupo, à medida que ele galgava maiores espaços no ambiente institucional (Escorel, 1998; Fleury, 1995; Fleury, 1997; Rodriguez Neto, 2003; Gerschman, 1995; Paim, 2008).

É significativo o fato de os membros do Cebes terem obtido importantes cargos na estrutura governamental ao longo do período, ocorrência que demonstra a porosidade da política à influência das propostas e intervenções do Centro. Dando sentido mais amplo à participação, não só demarcaram um espaço de atuação, como também reivindicaram o reconhecimento de seu papel no conjunto das transformações conjunturais. A ascensão profissional - característica marcante dos membros do Centro - esteve fortemente relacionada com a integração, na administração pública, de quadros pertencentes ao Cebes, que chegaram a ocupar importantes cargos no alto escalão do governo nas diferentes conjunturas políticas no período. Do amplo rol de nomes, poderíamos destacar os casos emblemáticos de Eleutério Rodriguez Neto, coordenador de Planejamento e Estudos da Secretaria de Serviços Médicos do Ministério da Previdência e Assistência Social (1980) e o sanitarista Antônio Sérgio da Silva Arouca, presidente da Fundação Oswaldo Cruz (1988). Assim, mesmo quando se depararam com graves dificuldades financeiras - como a crise que abateu o Centro em 1979, suspendendo, por um ano, suas atividades - seus integrantes agiam no intuito de superar tal problemática. Dessa forma, os membros estariam dando à inserção no Cebes um sentido mais amplo, demarcando um espaço de atuação e galgando espaço no comando das políticas.

É preciso assinalar que, durante os primeiros tempos, outro gênero de publicação com o objetivo de propagar o ideário do grupo foi criado e agregou material à linha de reflexão da revista. Trata-se da série de livros editados a partir de 1978 pelo Cebes em parceria com a Editora Hucitec, tendo em mira um público leitor vinculado a instituições acadêmicas, o que conferia de vez caráter acadêmico aos estudos realizados. A escolha da editora representa 


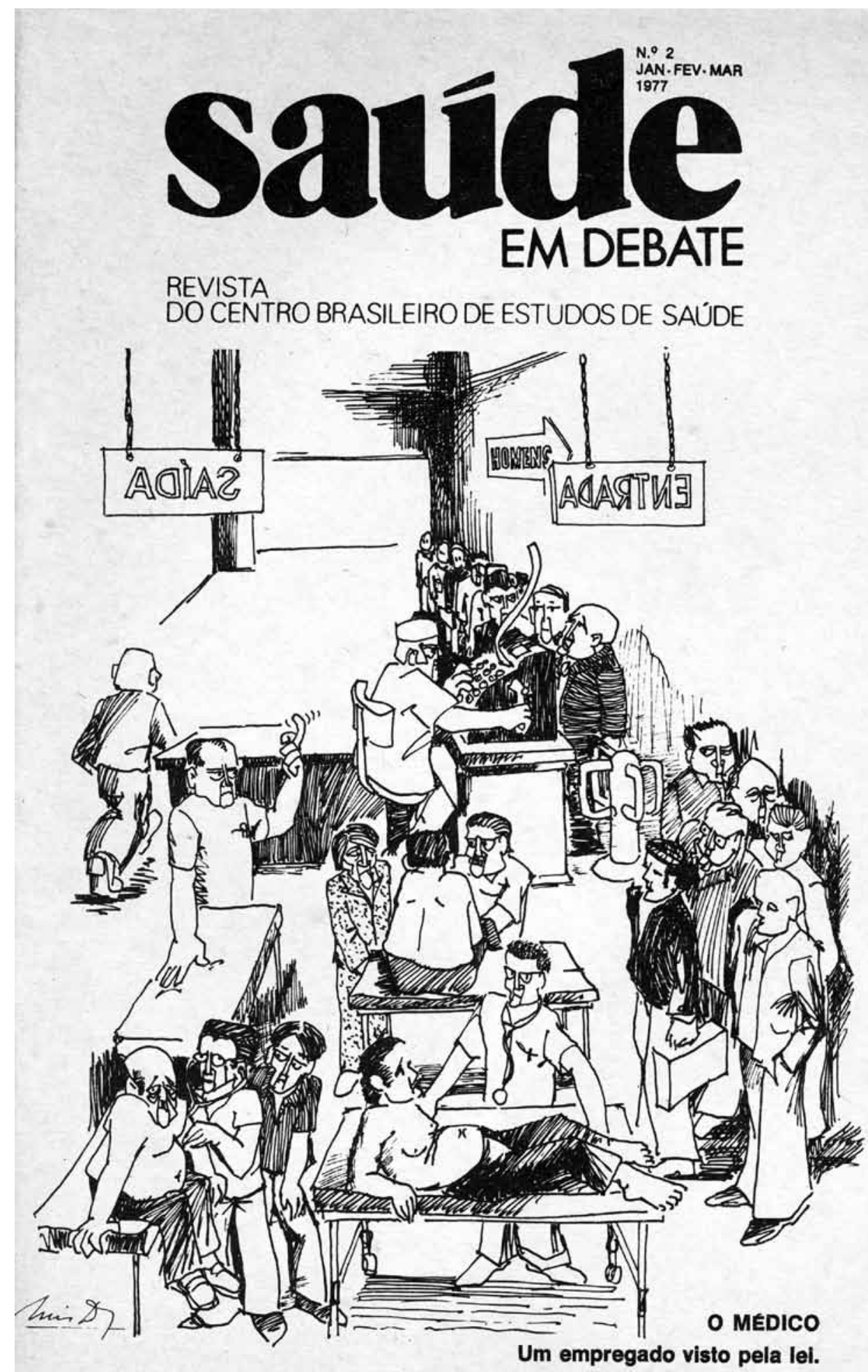

Figura 2: Capa de Saúde em Debate, número 2 (jan.-mar. 1977) 

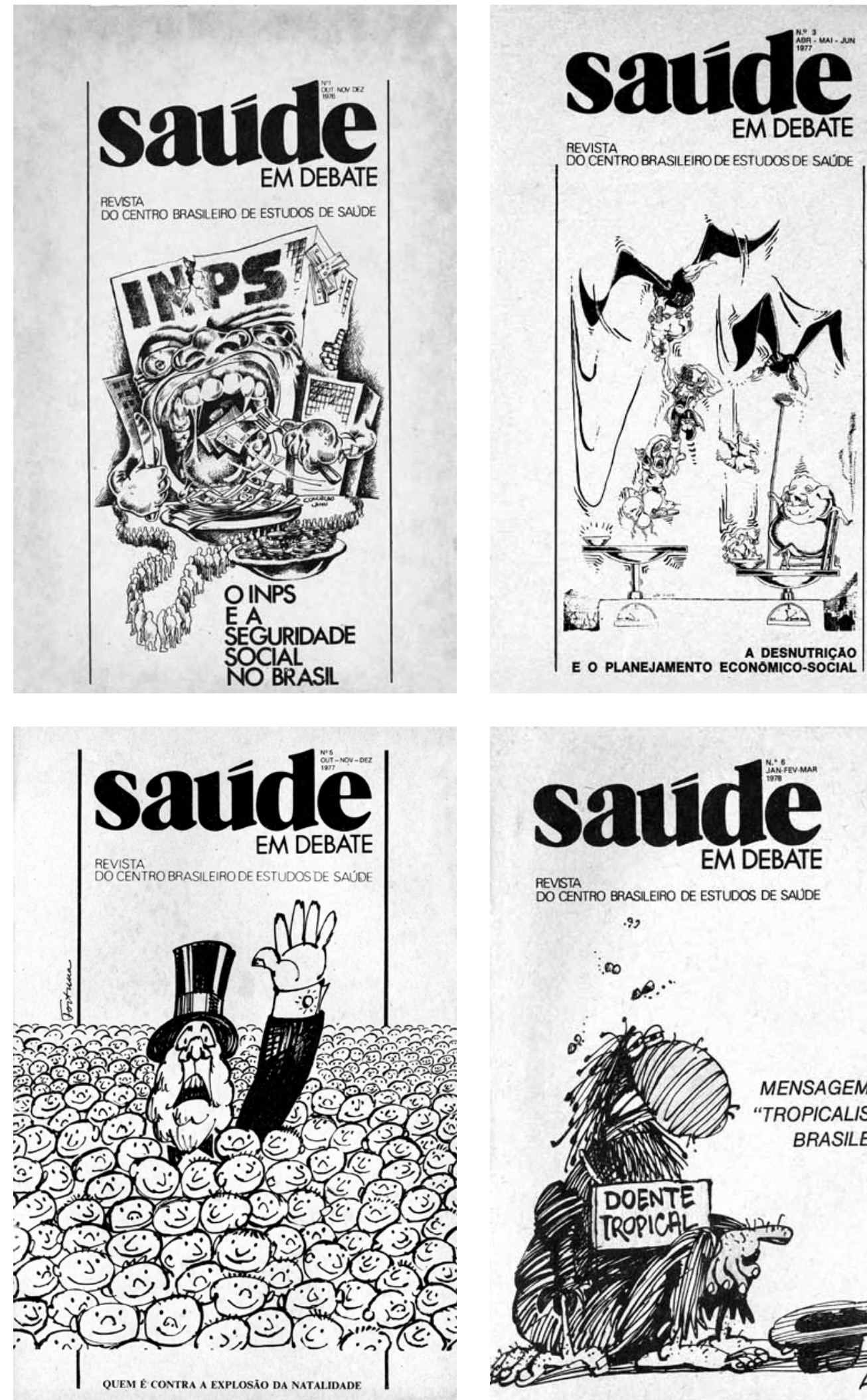

REVSTA

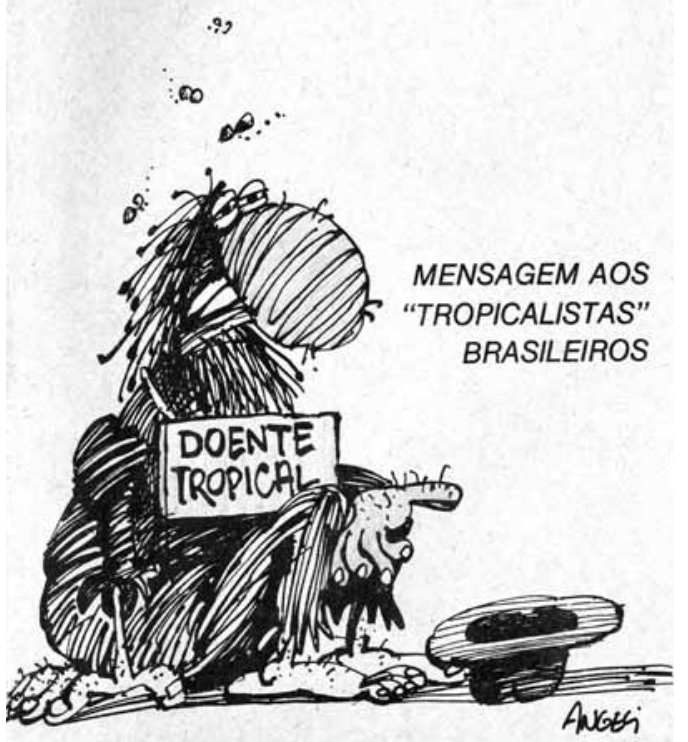

Figuras 3, 4, 5 e 6: Capas de Saúde em Debate, números 1 (out.-dez. 1976), 3 (abr.-jun. 1977), 5 (out.-dez. 1977) e 6 (jan.-mar. 1978) 
outro indicativo da proximidade que o Centro mantinha com a academia. A Hucitec foi fundada em 1971 por Artur Neves, Flávio George Aderaldo, Adalgisa Pereira da Silva e Hanna Augusta Rothschild, profissionais ligados ao mercado editorial. O nome Hucitec foi criado por Maurício Rocha e Silva, professor titular de farmacologia da Universidade de São Paulo, e é uma composição dos substantivos humanismo, ciência e tecnologia.

Apesar de tais publicações guardarem diferenças importantes em relação à Saúde em Debate, seja na forma de organização, seja na estrutura textual, no aspecto físico ou na temporalidade, já sinalizavam alguns pontos importantes, relevantes para a compreensão da referida revista. Um deles é o interesse do Centro em se comunicar com seus membros por meio de uma obra mais variada e acessível aos diferentes perfis existentes (Dutra, 2005, p.30); outro é o de fortalecer a entidade com os recursos obtidos por meio da comercialização dos livros, assegurando-lhe o montante necessário ao custeio do aluguel da sala em que estava instalada, bem como de atividades administrativas rotineiras.

Para finalizar, gostaríamos de ressaltar a importância de um estudo que busque valorizar as fontes primárias na análise histórica do processo da reforma sanitária brasileira dos anos 1980, a exemplo do que não deixou de ser empreendido com relação ao movimento sanitário das primeiras décadas do século XX (Hochman, 1998). O extenso e diversificado conteúdo da revista Saúde em Debate convida a um exame de seus artigos como imagens cambiantes do caleidoscópio da saúde coletiva, sobretudo nos dez anos subsequentes a sua criação, em que se constituiu em fórum privilegiado dos debates e controvérsias em torno do processo de reforma. Afinal, as discussões que deixaram suas marcas nas páginas do periódico põem em jogo, de modo emblemático, valores e objetivos, por vezes francamente opostos, de diferentes atores que se revelaram cruciais no processo da reforma sanitária ao longo dos anos 1970 e 1980. Nesse sentido, essa pesquisa procurou identificar os fragmentos e as cores, escolher o jogo de espelhos e, por fim, fixar a imagem do caleidoscópio que será examinado.

\section{REFERÊNCIAS}

AROUCA, Sérgio.

O dilema preventivista: contribuição para a compreensão crítica da medicina preventiva. Rio de Janeiro: Editora Fiocruz. 2003.

AROUCA, Sérgio.

A história natural das doenças. Saúde em Debate, São Paulo, n.1, p.15-19. 1976.

\section{CEBES}

Centro Brasileiro de Estudos de Saúde. Estatuto do Cebes. São Paulo: s.n. 1976.

DUTRA, Eliane Regina de Freitas. Rebeldes literários da República: história e identidade nacional no Almanaque Garnier. Belo Horizonte: Editora Humanitas. 2005.

ESCOREL, Sarah.

Reviravolta na saúde: origem e articulação do movimento sanitário. Rio de Janeiro: Editora Fiocruz. 1998.
ESCOREL, Sarah; NASCIMENTO, Dilene Raimundo do; EDLER, Flavio Coelho. As origens da reforma sanitária e do SUS. In: Lima, Nísia Trindade et al. (Org.). Saúde e democracia: história e perspectivas do SUS. Rio de Janeiro: Fiocruz, p.59-81. 2005.

FLEURY, Sônia Maria.

Saúde e democracia: a luta do Cebes. São Paulo: Lemos Editorial. 1997.

FLEURY, Sônia Maria.

Reforma sanitária: em busca de uma teoria. São Paulo: Editora Cortez. 1995.

GERSCHMAN, Silvia.

A democracia inconclusa: um estudo da reforma sanitária brasileira. Rio de Janeiro: Editora Fiocruz. 1995. 
HOCHMAN, Gilberto.

A era do saneamento: as bases da política de saúde pública no Brasil. São Paulo: Hucitec. 1998.

PAIM, Jairnilson Silva.

Reforma sanitária brasileira: contribuição para a compreensão e crítica. v.1. Salvador: Edufba; Rio de Janeiro: Fiocruz. 2008.
RODRIGUEZ NETO, Eleutério.

Saúde: promessas e limites da Constituição. Rio de Janeiro: Editora Fiocruz. 2003.

\section{$\rightarrow \rightarrow \rightarrow<<<$}

